\title{
Impacto do método canguru sobre o aleitamento materno de recém-nascidos pré-termo no Brasil: uma revisão integrativa
}

\author{
Impact of the kangaroo method of breastfeeding of preterm \\ newborn infants in Brazil: an integrative review
}

Fernanda Nascimento Alves (https://orcid.org/0000-0003-0447-4230) ${ }^{1}$

Vivian Mara Gonçalves de Oliveira Azevedo (https://orcid.org/0000-0002-7514-1508) ${ }^{1}$

Magda Regina Silva Moura (https://orcid.org/0000-0003-1847-1612) ${ }^{2}$

Daniela Marques de Lima Mota Ferreira (https://orcid.org/0000-0003-1378-3051) ${ }^{1}$

Cristina Guimarães Arantes Araújo (https://orcid.org/0000-0001-8118-104X) ${ }^{1}$

Clesnan Mendes-Rodrigues (https://orcid.org/0000-0002-8871-7422) ${ }^{1}$

Paula Carolina Bejo Wolkers (https://orcid.org/0000-0001-8265-198X) ${ }^{1}$

${ }^{1}$ Ambulatório de Pediatria, Hospital de Clínicas,

Universidade Federal de Uberlândia. Av. Pará 1720

Umuarama. 38400-902

Uberlândia

MG Brasil.paulawolkers@

yahoo.com.br

${ }^{2}$ Faculdade de Medicina,

Instituto Master de Ensino

Presidente Antônio Carlos

(IMEPAC Araguari).

Araguari MG Brasil.

\begin{abstract}
The scope of this integrative review of the literature was to assess if the Kangaroo-Mother Care Method as implemented in Brazil, from the first stage to outpatient follow-up, has an influence on breastfeeding. Brazilian research published in national and international journals in Portuguese, English or Spanish in the leading research databases between the years 2000 to 2017 was included, with full articles available and theme related to the scope of this study. A total of 1328 articles were located and articles not conducted in Brazil, literature review articles and themes not related to the Kangaroo-Mother Care Method were excluded, with 21 studies eventually being selected. The research results indicated a positive influence of the Kangaroo-Mother Care Method on breastfeeding and establishing a mother-child bond. However, the third stage or outpatient follow-up proved not to be effective in maintaining breastfeeding. Greater participation of primary care in home care provided to preterm newborns is necessary, with a view to promoting exclusive breastfeeding up to six months of age and extended up to two years of age.

Key words Intensive Neonatal Therapy, Public health policies, Kangaroo-Mother Care Method, Breastfeeding
\end{abstract}

Resumo Esta revisão integrativa da literatura teve como objetivo verificar se o Método Canguru, conforme instituído no Brasil, desde a primeira etapa até o acompanhamento ambulatorial, tem influência sobre o aleitamento materno. Foram incluídas pesquisas realizadas no Brasil, publicadas em periódicos nacionais e internacionais, nas principais bases de dados, em português, inglês ou espanhol, nos anos de 2000 a 2017, disponiveis na integra e com a temática relacionada com o objetivo deste estudo. Foram encontrados 1328 artigos sendo excluídos artigos não realizados no Brasil, artigos de revisão da literatura e de temáticas não relacionadas com o Método Canguru, sendo então selecionados 21 estudos. As pesquisas encontradas apontaram para uma influência positiva do Método Canguru sobre o aleitamento materno e estabelecimento de vínculo entre mãe-filho. No entanto, a terceira etapa ou acompanhamento ambulatorial, não se mostrou eficaz na manutenção do aleitamento materno. Faz-se necessário maior participação da atenção básica nos cuidados domiciliares prestados ao recém-nascido pré-termo, com vistas à promoção do aleitamento materno exclusivo até os seis meses de idade e complementado até os dois anos.

Palavras-chave Terapia Intensiva Neonatal, Políticas públicas de saúde, Método Canguru, Aleitamento Materno 


\section{Introdução}

O leite materno é considerado padrão ouro para alimentação de recém-nascidos $(\mathrm{RNs})^{1}$, principalmente os pré-termo (RNs com idade gestacional $<37$ semanas) $)^{2}$, devido às suas propriedades em prevenir afecções relacionadas com a prematuridade como enterocolite necrosante ${ }^{3,4}$, sepse de início tardio ${ }^{5}$, infecção do trato urinário $^{6}$, doenças respiratórias ${ }^{7}$, incluindo a redução de tempo de internação ${ }^{5}$ e reinternações ${ }^{2}$.

No entanto, para o grupo de recém-nascidos pré-termo (RNPT) em especial a incidência de aleitamento materno exclusivo (AME) é ainda mais reduzida ${ }^{8}$. Furman et al. ${ }^{8}$, descreveram em estudo observacional prospectivo, que das 87 mães de RNs de baixo peso ( $<1500$ gramas) que pretendiam amamentar, somente 30 estavam em aleitamento na $40^{\text {a }}$ semana de idade corrigida e apenas $14 \mathrm{o}$ mantiveram no quarto mês. Isto ocorre por múltiplas variáveis, como imaturidade fisiológica, neurológica e do sistema sensóriomotor oral, baixa frequência de sucção devido à instabilidade do RNPT e tempo prolongado de internação, ocasionando início tardio da amamentação e consequentemente diminuição da expressão de leite. Fatores psicológicos maternos, gerados pela insegurança e ansiedade quanto à situação de estresse causada pelo nascimento prematuro também contribuem para o insucesso na amamentação $0^{9-11}$.

Idealizado na Colômbia em 1978, o Cuidado Mãe-Canguru (CMC) foi criado como alternativa ao cuidado tradicional. Devido à escassez de recursos, era comum o compartilhamento de incubadoras entre dois ou mais RNs, causando altos índices de infecção cruzada, além de elevadas taxas de abandono materno, ocasionado pelo não estabelecimento de vínculo entre mãe e filho gerado pelo afastamento em internações prolongadas $^{12}$.

O CMC consistia em manter o RNPT após estabilização clínica, entre os seios maternos, em contato pele a pele, na posição supina, mantendo-o aquecido pelo calor de sua mãe, pelo maior tempo que fosse possível, o que possibilitava a alta precoce devido ao uso das incubadoras por menor tempo e maior aproximação entre a díade $^{13}$.

Nos países desenvolvidos, onde o CMC não tinha caráter substitutivo de recursos e havia disponibilidade de tecnologias direcionadas a atenção à saúde perinatal, o mesmo não trouxe impacto no aumento da sobrevida dos neonatos. Porém foi observado êxito quanto ao aumento do vínculo entre mãe e bebê, maior confiança da família no manuseio dos cuidados ao RN de baixo peso e estímulo ao aleitamento materno ${ }^{13}$.

Nota-se que as formas de cuidado adotadas variavam de acordo com as especificidades e necessidades de cada país, sendo observado como característica comum a posição canguru. No Brasil, é importante ressaltar que o CMC foi usado apenas como inspiração para a elaboração da Norma de Atenção Humanizada ao Recém-Nascido de Baixo Peso - Método Canguru. Lançado em dezembro de 1999 como política pública de saúde, o Método Canguru (MC) é desenvolvido em três etapas, tendo como princípios o cuidado centrado na família, a redução de fatores estressores ao RN, o incentivo ao aleitamento materno e a promoção de vínculo ${ }^{14}$.

Com a criação da norma, estabeleceu-se a diferença entre Método Canguru e Posição Canguru. Segundo a definição do Ministério da Saúde em 2013:

Método Canguru é um modelo de assistência perinatal voltado para a melhoria da qualidade do cuidado, desenvolvido em três etapas conforme Portaria GM/MS no 1.683, de 12 de julho de 2007 que: parte dos princípios da atenção humanizada; reduz o tempo de separação entre mãe e recém-nascido e favorece o vínculo; permite um controle térmico adequado; contribui para a redução do risco de infecção hospitalar; reduz o estresse e a dor do recém-nascido; aumenta as taxas de aleitamento materno; melhora a qualidade do desenvolvimento neurocomportamental e psico-afetivo do recémnascido; propicia um melhor relacionamento da família com a equipe de saúde; possibilita maior competência e confiança dos pais no cuidado do seu filho inclusive após a alta hospitalar; reduz o número de reinternações; e contribui para a otimização dos leitos de Unidades de Terapia Intensiva e de Cuidados Intermediários Neonatais ${ }^{14}(p .7)$.

Ainda segundo definição de 2013 do Ministério da Saúde:

A posição canguru consiste em manter o recémnascido de baixo peso, em contato pele a pele, na posição vertical junto ao peito dos pais ou de outros familiares $^{14}(\mathrm{p} .19)$.

Conclui-se então que o posicionamento é apenas um princípio dentro de uma estratégia muito mais abrangente, que engloba além do contato pele a pele, o acolhimento do bebê e sua família, respeito às individualidades e envolvimento da mãe nos cuidados com o filho.

A primeira etapa, realizada ainda dentro das Unidades de Terapia Intensiva Neonatal (UTIN) tem como ênfase o acolhimento à família, redu- 
ção de estímulos estressores ao RNPT e estabelecimento de vínculo através do contato pele a pele. Já a segunda etapa, ocorre após a estabilização do RN, onde a mãe ficará internada junto ao filho nas Enfermarias de Cuidado Intermediário Canguru, realizando contato pele a pele por meio da posição canguru, com o objetivo de estabelecer o aleitamento materno, além de proporcionar maior confiança aos pais no cuidado com o RNPT. A terceira etapa ocorre após a alta hospitalar e consiste no acompanhamento ambulatorial intensivo, com o intuito de sanar as principais dificuldades encontradas no domicílio e assistir a família prematura até o RN atingir 2500 gramas ou até que a mesma apresente condições de alta ambulatorial $^{14}$.

A literatura internacional aponta para os benefícios da posição canguru no estabelecimento do aleitamento materno, porém estudos sobre o $\mathrm{MC}$ ainda são escassos. Isto se dá porque, o impacto do MC sobre a amamentação só pode ser testado em pesquisas realizadas no Brasil, devido ao fato de que este Método, conforme estabelecido na Norma de Atenção, contemplando primeira, segunda e terceira etapa, é praticado exclusivamente em nosso país. Pesquisa anterior sobre o MC realizada por Venancio e Almeida ${ }^{15}$, evidenciou impacto positivo do MC sobre a prática da amamentação. No entanto, tal revisão abordou pesquisas relacionadas à posição canguru em vários países, assim como os primeiros relatos de experiencias no Brasil, diferindo de nosso objetivo.

Sendo assim, o objetivo desta revisão é verificar a influência do MC, conforme instituído no Brasil, abrangendo desde a primeira etapa até o acompanhamento ambulatorial sobre o aleitamento materno de RNPT.

\section{Métodos}

Trata-se de uma revisão integrativa da literatura que teve como pergunta norteadora: O Método Canguru instituído no Brasil, abrangendo desde a primeira etapa até o acompanhamento ambulatorial, tem influência sobre o aleitamento materno de RNPT?

Foram incluídas pesquisas realizadas no Brasil, publicadas em periódicos nacionais e internacionais, nas bases de dados MEDLINE, Scielo, Scopus, CINAHL, Science Direct e Web of Science, em português, inglês ou espanhol, nos anos de 2000 a 2017, disponíveis na íntegra e com a temática relacionada com o impacto do MC no aleitamento materno para os RNPT brasileiros. Os descritores escolhidos constavam no DeCs (Descritores em Ciências da Saúde) e MeSH (Medical Subject Headings), sendo utilizado os descritores em língua inglesa: Kangaroo Mother Care, breastfeeding e infant, premature; e em língua portuguesa: Método Canguru, Amamentação e Recém-nascido Prematuro, com operador booleano AND.

A Norma de Atenção Humanizada ao Recém-Nascido de Baixo Peso - Método Canguru é exclusivamente brasileira e por isso excluímos pesquisas realizadas fora do país, também foram excluídas revisões da literatura da mesma temática, pesquisas de outros assuntos, além de outros artigos cujo tema não tratava do MC.

Nós optamos por excluir os artigos de revisão, pois utilizavam também pesquisas internacionais para compor seus resultados, o que não comtempla o foco estabelecido neste estudo. No entanto, os estudos realizados no Brasil sobre o MC citados nestas revisões foram também analisados.

Foram encontrados 1.328 artigos, procedeuse então a leitura dos títulos utilizando os critérios de inclusão e exclusão, após esta primeira filtragem procedeu-se a leitura dos resumos dos estudos por toda equipe executora, sendo então selecionados 21 estudos para compor a revisão. Na Figura 1 demonstramos como se deu a seleção dos artigos utilizados nesta revisão.

\section{Resultados}

No Quadro 1 elencamos os artigos quantitativos selecionados e no Quadro 2 os artigos com metodologia qualitativa, juntamente com seus objetivos, abordagem metodológica e principais resultados.

Após leitura minuciosa dos artigos selecionados foi possível agrupá-los em três categorias: "Método Canguru e influência nas taxas de aleitamento materno"17,18,20,21,24,25,27,28, "Vivências maternas no Método Canguru, construção de vínculo e seus reflexos para a amamentação"16,19,29,30,31,35,36 e "Aspectos relacionados ao desmame precoce em participantes do Método Canguru"22,23,26,31,32,34.

$\mathrm{Na}$ categoria "Método Canguru e influência nas taxas de aleitamento materno", observamos que em todas as pesquisas selecionadas, a prevalência de aleitamento materno, exclusivo e misto (seio materno e complemento), no momento da alta da segunda etapa foi superior ao uso de ape- 


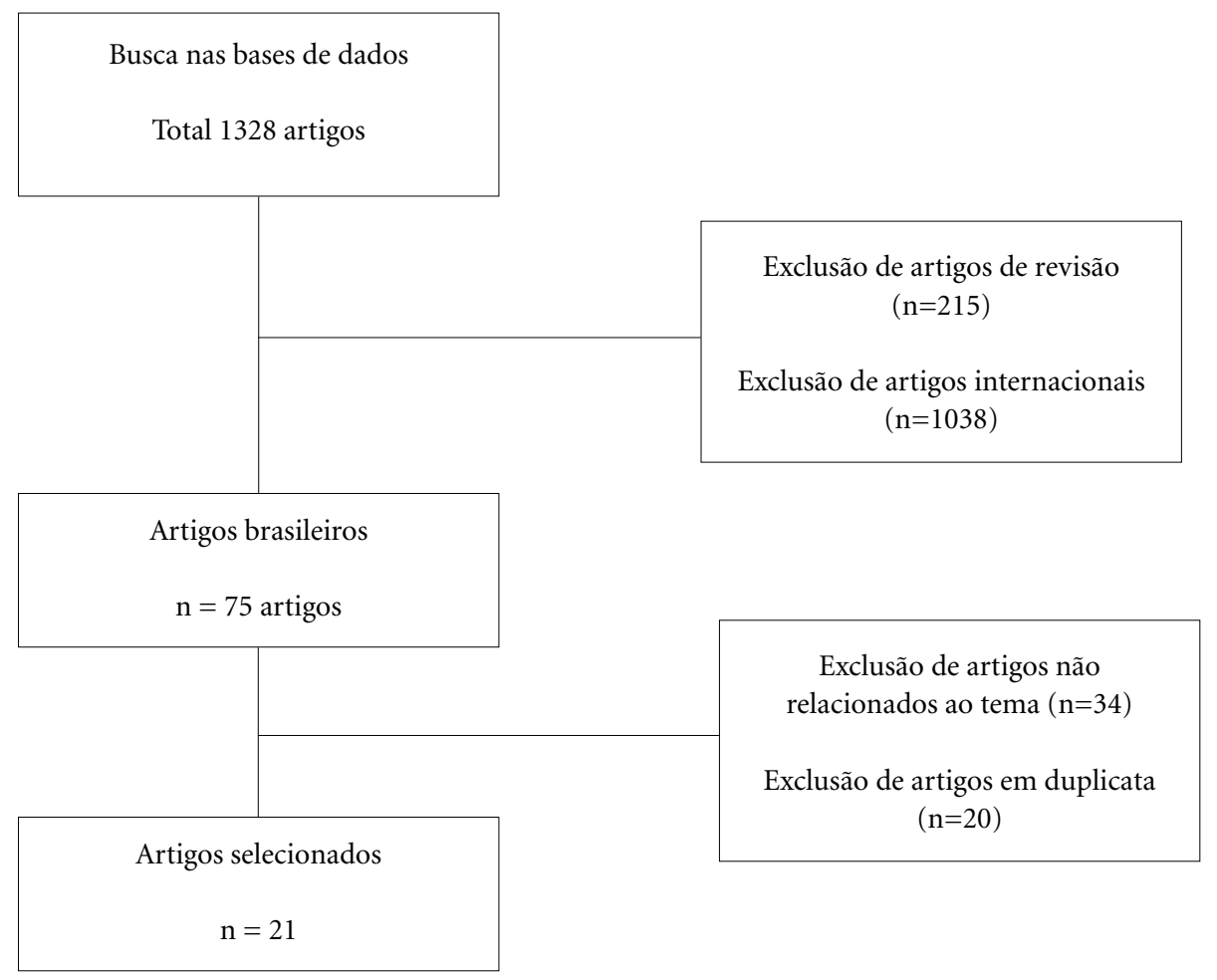

Figura 1. Fluxograma das etapas de busca e seleção dos artigos analisados.

nas fórmula $17,18,20,21,24,25,27,28$, assim como, quando comparado com as unidades convencionais, as unidades canguru obtiveram taxas superiores ${ }^{21,24}$.

A porcentagem de uso de fórmula foi crescente na alta da terceira etapa e nos ambulatórios de seguimento ${ }^{18,20,21,27}$, entretanto perdas consideráveis no número de bebês acompanhados foram registradas, gerando um possível viés nas amostras descritas.

Na categoria "Vivências maternas no Método Canguru, construção de vínculo e seus reflexos para a amamentação" os estudos evidenciaram que maior tempo de posição canguru favorece as trocas iniciais de contato entre mãe e filho, o que sugere maior estado de alerta e melhor disponibilidade do RN para interações durante a amamentação ${ }^{16}$. Além disso, o MC foi apontado como promotor de vínculo entre a díade ${ }^{29}$, influenciando na crescente percepção de autoefi- cácia materna com o decorrer das etapas, sendo proporcional às taxas de aleitamento materno ${ }^{19}$.

Já no agrupamento "Aspectos relacionados ao desmame precoce em participantes do Método Canguru" as principais causas descritas como dificultadoras da amamentação foram fatores culturais, como crença de leite fraco e pouco lei$\mathrm{te}^{26}$, costumes locais que valorizavam o uso de fórmula ${ }^{31}$, falta de apoio com as tarefas do $\operatorname{lar}^{34}$, necessidade de cuidar de outros filhos ${ }^{34}$, além do desaparecimento gradual do processo de ensino -aprendizagem em saúde ${ }^{32}$, podendo estar relacionado com a diminuição no número de consultas ambulatoriais ${ }^{23}$. A média de idade em que houve desmame total esteve entre 2 a 3 meses $^{22,26}$. A internação em enfermaria canguru foi apontada por um estudo como fator protetor para a permanência do aleitamento materno após a alta hospitalar ${ }^{22}$. 
Quadro 1. Fichamento dos artigos quantitativos selecionados.

\begin{tabular}{|c|c|c|c|}
\hline Título & Objetivo & $\begin{array}{c}\text { Tipo de estudo/ } \\
\text { Ano }\end{array}$ & Resultados \\
\hline $\begin{array}{l}\text { Relação da duração } \\
\text { da posição canguru e } \\
\text { interação mãe-filho } \\
\text { pré-termo na alta } \\
\text { hospitalar }^{16} \text {. }\end{array}$ & $\begin{array}{l}\text { Analisar a influência da } \\
\text { duração da Posição Canguru } \\
\text { nas interações iniciais da díade } \\
\text { mãe-filho pré-termo. }\end{array}$ & $\begin{array}{l}\text { Observacional } \\
\text { prospectivo/2017 }\end{array}$ & $\begin{array}{l}\text { Os dados apontam que o maior } \\
\text { tempo de Posição Canguru favorece } \\
\text { as trocas iniciais de contato entre o } \\
\text { filho pré-termo e a mãe, o que sugere } \\
\text { maior estado de alerta e melhor } \\
\text { disponibilidade do RN para interações } \\
\text { com a mãe durante a amamentação. }\end{array}$ \\
\hline $\begin{array}{l}\text { Posição canguru } \\
\text { em recém-nascidos } \\
\text { pré-termo de muito } \\
\text { baixo peso: estudo } \\
\text { descritivo }^{17} \text {. }\end{array}$ & $\begin{array}{l}\text { Descrever o número de períodos } \\
\text { em que os RNPT estiveram em } \\
\text { posição canguru ao longo da } \\
\text { internação e buscar relações } \\
\text { entre variáveis maternas e } \\
\text { neonatais com a realização da } \\
\text { posição canguru. }\end{array}$ & $\begin{array}{l}\text { Descritivo, } \\
\text { retrospectivo/ } \\
2017\end{array}$ & $\begin{array}{l}\text { Na alta hospitalar, } 29,7 \% \text { dos } \\
\text { RNs estavam em AME, } 48,6 \% \text { em } \\
\text { aleitamento materno misto e } 21,6 \% \\
\text { recebiam exclusivamente fórmula. }\end{array}$ \\
\hline $\begin{array}{l}\text { Recém-nascidos } \\
\text { prematuros assistidos } \\
\text { pelo Método } \\
\text { Canguru: avaliação } \\
\text { de uma coorte do } \\
\text { nascimento aos seis } \\
\text { meses }^{18} \text {. }\end{array}$ & $\begin{array}{l}\text { Avaliar a evolução clínica, } \\
\text { o crescimento e a taxa de } \\
\text { aleitamento materno exclusivo } \\
\text { de recém-nascidos prematuros } \\
\text { assistidos pelo Método } \\
\text { Canguru, ao nascimento, na alta } \\
\text { e aos seis meses de idade. }\end{array}$ & Coorte/2014 & $\begin{array}{l}\text { No momento da alta hospitalar 56,2\% } \\
\text { dos RNs estavam em AME, } 38,7 \% \\
\text { em aleitamento misto e 5,1\% apenas } \\
\text { fórmula. Aos seis meses, apenas } 14,4 \% \\
\text { dos bebês ainda encontravam-se em } \\
\text { AME, } 26,3 \% \text { em aleitamento misto e } \\
59,2 \% \text { em uso de fórmula. }\end{array}$ \\
\hline $\begin{array}{l}\text { Percepções maternas } \\
\text { no método canguru: } \\
\text { contato pele a pele, } \\
\text { amamentação e } \\
\text { autoeficácia }^{19} \text {. }\end{array}$ & $\begin{array}{l}\text { Descrever a prática da posição } \\
\text { canguru e de amamentação, } \\
\text { bem como avaliar a percepção } \\
\text { de auto-eficácia em relação aos } \\
\text { cuidados e à interação com } \\
\text { o neonato, ao longo das três } \\
\text { etapas do Método Canguru, } \\
\text { de mães de recém-nascidos } \\
\text { prematuros de baixo peso. }\end{array}$ & Descritivo/2013 & $\begin{array}{l}\text { O AME foi predominante nas três } \\
\text { etapas do MC. A percepção de auto- } \\
\text { eficácia materna foi crescente com } \\
\text { o passar das etapas, demonstrando } \\
\text { que o MC auxilia no processo de } \\
\text { maternagem e segurança da mãe na } \\
\text { realização dos cuidados com o RNPT. }\end{array}$ \\
\hline $\begin{array}{l}\text { Duração da } \\
\text { permanência em uma } \\
\text { unidade de terapia } \\
\text { intensiva neonatal } \\
\text { e sua associação } \\
\text { com baixas taxas de } \\
\text { aleitamento materno } \\
\text { exclusivo em bebês de } \\
\text { muito baixo peso }{ }^{20} \text {. } \\
\end{array}$ & $\begin{array}{l}\text { Determinar a taxa de } \\
\text { amamentação exclusiva em } \\
\text { lactentes de muito baixo peso, } \\
\text { assistidos pelo MC, na primeira } \\
\text { consulta de acompanhamento } \\
\text { ambulatorial e identificar os } \\
\text { fatores maternos e neonatais } \\
\text { associados. }\end{array}$ & Coorte/2011 & $\begin{array}{l}\text { Todos os RNs }(\mathrm{n}=119) \text { receberam } \\
\text { alta em AME. Destes } 119 \text { pacientes, } \\
88(75 \%) \text { retornaram para uma } \\
\text { visita de acompanhamento até uma } \\
\text { semana após a alta. Apenas } 22(25 \%) \\
\text { estavam em AME, } 63 \text { destes }(71,5 \%) \\
\text { receberam leite materno juntamente } \\
\text { com fórmula e } 3(3,5 \%) \text { apenas } \\
\text { fórmula. }\end{array}$ \\
\hline $\begin{array}{l}\text { Impacto do método } \\
\text { canguru nas taxas de } \\
\text { aleitamento materno } \\
\text { exclusivo em recém- } \\
\text { nascidos de baixo } \\
\text { peso }^{21} \text {. }\end{array}$ & $\begin{array}{l}\text { Avaliar o impacto do MC sobre } \\
\text { o AME nos seis primeiros meses } \\
\text { de vida em RNPTs. }\end{array}$ & Coorte/2010 & $\begin{array}{l}\text { A amamentação exclusiva foi superior } \\
\text { no grupo canguru na alta }(82,6 \text { versus } \\
0 \% ; \mathrm{p}=0,00) \text {, às quarenta semanas de } \\
\text { idade gestacional }(73,9 \text { versus } 31,6 \% ; \\
\mathrm{p}=0,01) \text {, aos três meses }(43,5 \text { versus } \\
5,0 \% ; \mathrm{p}=0,005) \text { e aos seis meses }(22,7 \\
\text { versus } 5,9 \% ; \mathrm{p}=0,20) \text { de vida. }\end{array}$ \\
\hline $\begin{array}{l}\text { Fatores que } \\
\text { influenciam o } \\
\text { desmame no recém- } \\
\text { nascido prematuro }{ }^{22} \text {. }\end{array}$ & $\begin{array}{l}\text { Verificar os principais fatores } \\
\text { que influenciam o desmame } \\
\text { em prematuros nascidos em } \\
\text { maternidade pública da cidade } \\
\text { de São Paulo. }\end{array}$ & Transversal/2010 & $\begin{array}{l}\text { A média de idade para o desmame } \\
\text { parcial foi de } 1,41 \pm 1,09 \text { meses e total } \\
2,93 \pm 1,54 \text { meses. Quanto menor a } \\
\text { idade de introdução da chupeta, mais } \\
\text { precoce o desmame parcial. Mães que } \\
\text { internaram na enfermaria canguru, } \\
\text { interromperam o aleitamento } \\
\text { materno mais tardiamente. }\end{array}$ \\
\hline
\end{tabular}


Quadro 1. Fichamento dos artigos quantitativos selecionados.

\begin{tabular}{|c|c|c|c|}
\hline Título & Objetivo & $\begin{array}{c}\text { Tipo de estudo/ } \\
\text { Ano }\end{array}$ & Resultados \\
\hline $\begin{array}{l}\text { Método Mãe } \\
\text { Canguru: uma } \\
\text { investigação da } \\
\text { prática domiciliar }^{23} \text {. }\end{array}$ & $\begin{array}{l}\text { Conhecer a prática domiciliar } \\
\text { do Método Mãe Canguru. }\end{array}$ & Descritivo/2010 & $\begin{array}{l}\text { No domicílio, 93,3\% das mães estavam } \\
\text { realizando adequadamente a posição } \\
\text { canguru, } 86,7 \% \text { delas amamentando } \\
\text { tecnicamente correto. Tarefas do lar } \\
\text { e falta de recurso financeiro foram } \\
\text { apontados como principal obstáculo } \\
\text { para a realização da prática. }\end{array}$ \\
\hline $\begin{array}{l}\text { Avaliação dos } \\
\text { resultados neonatais } \\
\text { do método canguru } \\
\text { no Brasil }{ }^{24} \text {. }\end{array}$ & $\begin{array}{l}\text { Avaliar os resultados do Método } \\
\text { Canguru no Brasil. }\end{array}$ & Coorte/2008 & $\begin{array}{l}\text { As unidades canguru tiveram } \\
\text { desempenho superior em relação a } \\
\text { unidades convencionais nas taxas de } \\
\text { AME na alta hospitalar }(69,2 \text { versus } \\
23,8 \%, p=0,022) \text {. }\end{array}$ \\
\hline $\begin{array}{l}\text { Método Mãe- } \\
\text { Canguru: evolução } \\
\text { ponderal de recém- } \\
\text { nascidos }{ }^{25} \text {. }\end{array}$ & $\begin{array}{l}\text { Analisar a evolução ponderal } \\
\text { de recém-nascidos inseridos na } \\
\text { segunda etapa do MC e analisar } \\
\text { a influência do aleitamento } \\
\text { materno exclusivo no mesmo. } \\
\end{array}$ & $\begin{array}{l}\text { Descritivo, } \\
\text { prospectivo/ } \\
2007\end{array}$ & $\begin{array}{l}\text { A taxa de AME na alta da segunda } \\
\text { etapa foi de } 68,2 \% \text { dos } 22 \mathrm{RNs} \\
\text { avaliados. }\end{array}$ \\
\hline $\begin{array}{l}\text { Desmame precoce } \\
\text { em prematuros } \\
\text { participantes do } \\
\text { Método Mãe- } \\
\text { Canguru }^{26} \text {. }\end{array}$ & $\begin{array}{l}\text { Identificar a prevalência e as } \\
\text { causas de desmame precoce } \\
\text { nos recém-nascidos pré-termo, } \\
\text { participantes do Método Mãe } \\
\text { Canguru. }\end{array}$ & Transversal/2007 & $\begin{array}{l}\text { Todos os bebês se encontravam em } \\
\text { AME na alta hospitalar. O percentual } \\
\text { de desmame foi de } 27,3 \% \text {, com maior } \\
\text { ocorrência no terceiro mês de vida, } \\
\text { constatado no período dos retornos. A } \\
\text { causa de desmame precoce de maior } \\
\text { prevalência foi relacionada a fatores } \\
\text { socioculturais como crença de leite } \\
\text { fraco e pouco leite. }\end{array}$ \\
\hline $\begin{array}{l}\text { O método mãe } \\
\text { canguru em uma } \\
\text { maternidade do Rio } \\
\text { de Janeiro 2000- } \\
\text { 2002: necessidades da } \\
\text { criança e demanda } \\
\text { de educação em } \\
\text { saúde para os pais }{ }^{27} \text {. }\end{array}$ & $\begin{array}{l}\text { Caracterizar os neonatos } \\
\text { participantes das etapas } \\
\text { intra-hospitalares e analisar } \\
\text { as necessidades de cuidados } \\
\text { especiais na alta hospitalar e } \\
\text { as demandas dos pais para a } \\
\text { educação em saúde. }\end{array}$ & Descritivo/2006 & $\begin{array}{l}\text { A amamentação exclusiva atingiu } \\
51,7 \% \text { na primeira etapa, } 93 \% \\
\text { na segunda e } 15,1 \% \text { na terceira } \\
\text { (ambulatório). Após a alta } \\
\text { hospitalar, } 84,9 \% \text { apresentaram } \\
\text { necessidades de cuidados especiais } \\
\text { (de desenvolvimento, tecnológico } \\
\text { e medicamentoso), os quais } \\
\text { apontaram, na terceira etapa, para } \\
\text { uma demanda de educação familiar } \\
\text { sobre aleitamento materno e cuidados } \\
\text { relativos às necessidades da criança. }\end{array}$ \\
\hline $\begin{array}{l}\text { Estudo descritivo } \\
\text { do perfil clínico } \\
\text { nutricional e } \\
\text { do seguimento } \\
\text { ambulatorial de } \\
\text { recém-nascidos } \\
\text { prematuros } \\
\text { atendidos no } \\
\text { Programa Método } \\
\text { Mãe-Canguru }{ }^{28} \text {. }\end{array}$ & $\begin{array}{l}\text { Descrever o perfil de recém- } \\
\text { nascidos prematuros que } \\
\text { participaram do Programa } \\
\text { Método Mãe-Canguru, e o } \\
\text { seguimento ambulatorial e } \\
\text { eventuais correlações entre esses } \\
\text { descritores. }\end{array}$ & Descritivo/2006 & $\begin{array}{l}\text { O início da alimentação em seio } \\
\text { materno exclusivo correspondeu à } \\
\text { idade gestacional de } 35,3 \text { semanas } \\
\text { e } 18,6 \text { dias de vida. Receberam alta } \\
\text { hospitalar com } 29 \text { dias, peso } 1.734 \\
\text { g e seio materno exclusivo em } \\
85,7 \% . \text { Observamos amamentação } \\
\text { predominante em } 60,3 \% \text { aos } 6 \text { meses. }\end{array}$ \\
\hline
\end{tabular}

RN: Recém-nascido, AME: Aleitamento Materno Exclusivo, RNPT: Recém-nascido Pré-termo, MC: Método Canguru, UTIN: Unidade de Terapia Intensiva Neonatal.

Fonte: Estudos selecionados para integrar a revisão. 
Quadro 2. Fichamento dos artigos qualitativos selecionados.

\begin{tabular}{|c|c|c|c|}
\hline Título & Objetivo & \begin{tabular}{|c|} 
Tipo de \\
estudo/Ano
\end{tabular} & Resultados \\
\hline $\begin{array}{l}\text { Atenção humanizada } \\
\text { ao recém-nascido de } \\
\text { baixo-peso (método } \\
\text { mãe canguru): } \\
\text { percepções de } \\
\text { puérperas }^{29} \text {. }\end{array}$ & $\begin{array}{l}\text { Conhecer as percepções de } \\
\text { puérperas frente à utilização } \\
\text { do Método Mãe Canguru. }\end{array}$ & $\begin{array}{l}\text { Qualitativo/ } \\
2010\end{array}$ & $\begin{array}{l}\text { As mães relataram maior aproximação } \\
\text { com os RNs, promovida pelo MC, além } \\
\text { de fortalecer o vínculo, fazendo com } \\
\text { que o RNPT se alimente ao seio com } \\
\text { maior frequência. }\end{array}$ \\
\hline $\begin{array}{l}\text { Terceira etapa } \\
\text { método canguru: } \\
\text { convergências de } \\
\text { práticas investigativas } \\
\text { e cuidado com famílias } \\
\text { em atendimento } \\
\text { ambulatorial }^{30} \text {. }\end{array}$ & $\begin{array}{l}\text { Investigar a experiência no } \\
\text { processo de adaptação de } \\
\text { famílias na terceira etapa } \\
\text { do Método Canguru com } \\
\text { recém-nascidos pré-termo e/ } \\
\text { ou de baixo peso. }\end{array}$ & $\begin{array}{l}\text { Qualitativo/ } \\
2010\end{array}$ & $\begin{array}{l}\text { Os resultados mostraram a necessidade } \\
\text { de fortalecer o papel da família na } \\
\text { desospitalização, uma vez que a } \\
\text { continuidade do aleitamento materno } \\
\text { foi relacionada à maneira com que os } \\
\text { pais o valorizavam e lidavam com as } \\
\text { dificuldades encontradas no dia a dia. }\end{array}$ \\
\hline $\begin{array}{l}\text { Reconfigurado o leite } \\
\text { materno insuficiente } \\
\text { como um problema } \\
\text { sociossomático: mães } \\
\text { de bebês prematuros } \\
\text { usando o método } \\
\text { canguru no Brasil }^{31} \text {. }\end{array}$ & $\begin{array}{l}\text { Avaliar como o julgamento } \\
\text { de leite materno insuficiente } \\
\text { foi interpretado pelas mães } \\
\text { que foram assistidas pelo } \\
\text { Método Canguru, em seu } \\
\text { contexto social. }\end{array}$ & $\begin{array}{l}\text { Qualitativo/ } \\
2009\end{array}$ & $\begin{array}{l}\text { Falta de apoio clínico ambulatorial, } \\
\text { normas locais conflitantes para cuidar e } \\
\text { alimentar RNPTs, restrições econômicas } \\
\text { e descontinuidade nos modelos de } \\
\text { cuidados de saúde levaram as mães } \\
\text { a perder a confiança na capacidade } \\
\text { de amamentação, induzindo-as a } \\
\text { substituírem a amamentação exclusiva } \\
\text { por alimentação mista ou fórmulas. }\end{array}$ \\
\hline $\begin{array}{l}\text { A prática da } \\
\text { amamentação após o } \\
\text { método mãe canguru } \\
\text { no Rio de Janeiro: } \\
\text { a necessidade de } \\
\text { educação em saúde } \\
\text { e intervenção de } \\
\text { Enfermagem no } \\
\text { domicílio }^{32} \text {. }\end{array}$ & \begin{tabular}{|l|} 
Analisar como o \\
conhecimento sobre \\
amamentação exclusiva foi \\
incorporado no contexto dos \\
domicílios.
\end{tabular} & $\begin{array}{l}\text { Qualitativo/ } \\
2009\end{array}$ & $\begin{array}{l}\text { Nenhuma das mães participantes estava } \\
\text { realizando a posição canguru um mês } \\
\text { após a alta hospitalar. Foi identificado: } \\
\text { o desaparecimento gradual do processo } \\
\text { de ensino-aprendizagem; a falta de } \\
\text { educação em saúde na comunidade; } \\
\text { consultas de acompanhamento restritas } \\
\text { a intervenções médicas em ambulatório } \\
\text { e a não implementação do MC em casa } \\
\text { como fatores dificultadores do AME no } \\
\text { contexto de saúde do Rio de Janeiro. }\end{array}$ \\
\hline $\begin{array}{l}\text { Amamentação exclusiva } \\
\text { de recém-nascidos } \\
\text { prematuros: percepções } \\
\text { e experiências de } \\
\text { lactantes usuárias de } \\
\text { um serviço público } \\
\text { especializado }{ }^{33} \text {. }\end{array}$ & $\begin{array}{l}\text { Investigar percepções e } \\
\text { vivências das mães de } \\
\text { RNPT que amamentaram } \\
\text { exclusivamente do } 4^{\circ} \text { ao } 6^{\circ} \\
\text { mês de vida. }\end{array}$ & $\begin{array}{l}\text { Qualitativo/ } \\
2008\end{array}$ & $\begin{array}{l}\text { A decisão de amamentar o RNPT está } \\
\text { relacionada ao reconhecimento da } \\
\text { importância do leite materno para a } \\
\text { saúde do filho. Contudo, o suporte } \\
\text { fornecido pela instituição, a partir do } \\
\text { apoio dos profissionais às mães dos RNs, } \\
\text { revelou-se como elemento decisivo para a } \\
\text { prática exclusiva do aleitamento materno. }\end{array}$ \\
\hline $\begin{array}{l}\text { Percepção das mães } \\
\text { sobre o cuidado } \\
\text { do bebê de baixo } \\
\text { peso antes e após } \\
\text { implantação do Método } \\
\text { Mãe-Canguru em um } \\
\text { hospital público da } \\
\text { cidade de São Paulo, } \\
\text { Brasil }\end{array}$ & \begin{tabular}{|l|} 
Compreender sobre os \\
diferentes modos que as \\
famílias de baixa renda lidam \\
com o nascimento de um \\
bebê pré-termo, com vistas a \\
aprimorar a implantação do \\
Método Mãe-Canguru.
\end{tabular} & $\begin{array}{l}\text { Qualitativo/ } \\
2007\end{array}$ & $\begin{array}{l}\text { Em comparação às mães entrevistadas } \\
\text { antes da implantação do programa, } \\
\text { as mães-cangurus eram mais jovens, } \\
\text { mais escolarizadas, sem outros filhos, } \\
\text { recebiam mais ajuda nas tarefas } \\
\text { domésticas e relataram menos } \\
\text { dificuldades na amamentação. }\end{array}$ \\
\hline
\end{tabular}


Quadro 2. Fichamento dos artigos qualitativos selecionados.

\begin{tabular}{|l|l|l|l|}
\hline \multicolumn{1}{|c|}{ Título } & \multicolumn{1}{|c|}{ Objetivo } & $\begin{array}{l}\text { Tipo de } \\
\text { estudo/Ano }\end{array}$ & \multicolumn{1}{c|}{ Resultados } \\
\hline $\begin{array}{l}\text { A formação do apego } \\
\text { pais/recém-nascido } \\
\text { pré-termo e/ou de } \\
\text { baixo peso no método } \\
\text { mãe-canguru: uma } \\
\text { contribuição da } \\
\text { enfermagem }\end{array}$ & $\begin{array}{l}\text { Identificar e analisar os } \\
\text { aspectos promotores e } \\
\text { complicadores do processo } \\
\text { de formação do apego entre } \\
\text { pais e filhos pré-termo e/ } \\
\text { ou de baixo peso durante } \\
\text { a prática do Método Mãe- } \\
\text { Canguru. }\end{array}$ & $\begin{array}{l}\text { Qualitativo/ } \\
2007\end{array}$ & $\begin{array}{l}\text { O desconhecimento e inabilidade dos } \\
\text { pais em relação à imaturidade do RN } \\
\text { para iniciar e manter o processo de } \\
\text { amamentação foi apresentado como } \\
\text { um fator dificultador na formação de } \\
\text { vínculo. }\end{array}$ \\
\hline $\begin{array}{l}\text { As representações } \\
\text { sociais do ações } \\
\text { sociais do aleitamento } \\
\text { materno para mães de } \\
\text { prematuros em unidade } \\
\text { de cuidado cangurus }\end{array}$ & $\begin{array}{l}\text { Os objetivos do estudo } \\
\text { foram identificar as } \\
\text { representações sociais sobre } \\
\text { aleitamento materno de } \\
\text { pré-termo, em unidade de } \\
\text { Cuidado Canguru, sob a } \\
\text { óptica das mães que estão } \\
\text { amamentando, e descrever } \\
\text { os conflitos e contradições } \\
\text { que eles vivenciam nesse } \\
\text { contexto institucional. }\end{array}$ & Qualitativo// & $\begin{array}{l}\text { As representações encontradas são: os } \\
\text { bebês saudáveis são alimentados no } \\
\text { peito, o leite materno confere a proteção } \\
\text { e a preservação da vida de uma criança } \\
\text { prematura, o aleitamento materno } \\
\text { é o complemento da maternidade e } \\
\text { amamentar um bebê prematuro é uma } \\
\text { experiência difícil e desgastante. Os } \\
\text { conflitos são decorrentes da assimilação } \\
\text { de conteúdos e discurso técnico, sucção } \\
\text { tardia e representações sobre leite } \\
\text { materno }\end{array}$ \\
\hline
\end{tabular}

RN: Recém-nascido, AME: Aleitamento Materno Exclusivo, RNPT: Recém-nascido Pré-termo, MC: Método Canguru, UTIN: Unidade de Terapia Intensiva Neonatal.

Fonte: Estudos selecionados para integrar a revisão.

\section{Discussão}

Nos estudos selecionados observamos em sua maioria, elevadas taxas de aleitamento materno exclusivo e aleitamento materno misto no momento da alta hospitalar para os RNs acompanhados pelo $\mathrm{MC}^{17,18,20,21,24,25,27,28}$. Dados internacionais semelhantes foram descritos por Charpak et al. ${ }^{37}$, Ludington-Hoe et al. ${ }^{38}$, Gathwala et al. ${ }^{39}$, Thukral et al. ${ }^{40}$, Heidarzadeh et al. ${ }^{41}$, considerando o CMC. As enfermarias Canguru, atualmente definidas como Unidade de Cuidado Intermediário Neonatal Canguru (UCINca) também apresentaram resultados superiores quando comparadas aos cuidados tradicionais ${ }^{21,24}$. Corroborando com esse resultado, no estudo de Tully et al. ${ }^{42}$, as mães que praticavam a posição canguru, independentemente do grupo alocado aleatoriamente, eram mais propensas a fornecer o leite do que aquelas que não o praticavam.

Melhor estabelecimento de vínculo entre a díade mãe-bebê surgiu em nossa busca como fator associado na promoção da amamentação ${ }^{16,19,29}$. Pesquisas qualitativas que abordaram esta temática apontaram para discursos maternos mais confiantes, reconhecimento da importância do aleitamento materno para a recuperação do
$\mathrm{RNPT}^{33}$, além de melhor adaptação no processo de aprendizagem para com os cuidados com o filho ${ }^{19,29}$, gerado pela internação na segunda etapa do método. Porém o desconhecimento e a inabilidade dos pais com relação à imaturidade do RNPT no processo de cuidados e amamentação foram apontados como fatores dificultadores na construção de vínculo ${ }^{30,35,36}$.

A literatura comprova que mães de RNPT apresentam níveis de estresse e depressão pós -parto superiores quando comparadas a mães de RNs a termo ${ }^{43,44}$. Situações estressantes prolongadas podem afetar diretamente a lactação, devido a maior liberação de catecolaminas pelo organismo e, consequentemente, o bloqueio na produção de ocitocina, o que afeta negativamente a produção e ejeção láctea ${ }^{45}$. O estudo de Cruvinel e Macedo ${ }^{46}$ evidenciou que mães praticantes da posição canguru apresentaram melhora no estado de humor em comparação às mães que mantinham contato com o RN apenas pela incubadora. Bigelow et al. ${ }^{47}$ encontraram que mães que também realizavam o contato pele a pele, apresentavam escores mais baixos nas escalas de depressão na primeira semana de nascimento comparadas com as que não o realizavam. Alencar et al. ${ }^{48}$ observaram que no momento da admissão na 
UTIN, 37,3\% das mães avaliadas apresentavam sintomas de depressão, diminuindo para $16,9 \%$ após intervenção com o cuidado mãe-canguru.

A posição canguru foi apontada como favorecedora de trocas iniciais de contato entre o filho pré-termo e a mãe, sugerindo maior estado de alerta e melhor disponibilidade do RN para interações durante a amamentação ${ }^{16}$. Contudo, o estudo de Farias et al. ${ }^{17}$ apontou que a realização da posição canguru foi menos frequente que as oportunidades existentes, advindas da presença materna na unidade. Com hospitalizações que duraram de 18 a 136 dias, as mães estiveram com seus filhos em posição canguru uma média de $10,6 \pm 8,7$ períodos, sendo a mesma associada ao maior oferecimento de leite em livre demanda. Corroborando com este resultado, o estudo de Jayaraman et al. ${ }^{49}$ indicou que RNs de baixo peso ao nascer que iniciaram a posição canguru precocemente apresentaram taxas de AME superiores àqueles que iniciaram tardiamente.

Poucos estudos abordaram a terceira etapa do MC. Estes evidenciaram grandes quedas tanto das taxas de AME quanto das crianças acompanhadas nesta etapa do método. As principais causas descritas como dificultadoras da amamentação foram fatores culturais, como crença de leite fraco e pouco leite ${ }^{26}$, costumes locais que valorizavam o uso de fórmula ${ }^{31}$, falta de apoio com as tarefas do $\operatorname{lar}^{34}$, necessidade de cuidar de outros filhos ${ }^{34}$, além do desaparecimento gradual do processo de ensino-aprendizagem em saúde ${ }^{32}$, podendo estar relacionado com a diminuição no número de consultas ambulatoriais ${ }^{23}$.

Segundo Walty et al. $^{50}$, a rede social funciona como mediadora da amamentação tanto incentivando como desencorajando sua continuidade. Sendo assim faz-se necessário o estabelecimento da assistência ao RNPT após a alta hospitalar, para apoiar a mulher no processo da amamentação.

A redução do número de consultas ambulatoriais foi relatada em um dos estudos como fator de risco para o desmame precoce. Além disso, apontou-se que a dificuldade de acesso relacionada à distância da residência é uma barreira para a realização da terceira etapa nos ambulatórios especializados ${ }^{23,31,32}$. O estudo de Cabral e Rodrigues $^{32}$ evidenciou que aproximadamente metade dos RNs encaminhados à terceira etapa não aderiram ao programa de seguimento ambulatorial. Esta mesma pesquisa mostrou que embora as crianças recebessem alta da segunda etapa em AME, no acompanhamento da terceira etapa ocorreu uma redução expressiva desta porcentagem. Este resultado demonstra a potência do método para iniciar a amamentação e sua limitação para mantê-la no acompanhamento ambulatorial.

De acordo com Gontijo et al. ${ }^{51}$, até o ano de 2005 apenas 34,5\% dos hospitais maternidade capacitados pelo Ministério da Saúde implantaram as três etapas do MC. Nota-se que mesmo com a grande expansão após a criação da norma, a implantação das etapas ainda acontece com distribuição variável na rotina dos serviços públicos, sendo a articulação com a atenção primária à saúde, apesar de recomendada, ainda pouco estabelecida.

Segundo Aires et al. ${ }^{52}$ a dificuldade dos profissionais da atenção básica em dar continuidade aos cuidados estabelecidos pelo MC e atuar na terceira etapa parece estar relacionada ao limitado conhecimento dos mesmos para que se sintam seguros e aptos para tal. A frágil comunicação entre o hospital e a unidade básica de saúde impossibilita a continuidade do MC na atenção primária. Sendo assim, necessita-se de capacitação profissional e pactuações entre os diversos níveis de atenção à saúde para a efetivação da vinculação entre a terceira etapa do $\mathrm{MC}$ e a atenção primária.

Dessa forma, é importante ressaltar a necessidade de fortalecimento da atenção primária à saúde, do cuidado ampliado e em rede a essa população de forma integral, equânime e longitudinal com vistas na promoção do AME nos primeiros seis meses de vida e estendido até dois anos de idade ou mais.

\section{Conclusão}

A amamentação para o RNPT é um desafio, sendo o MC uma prática facilitadora do aleitamento materno. Entretanto, como o MC trata-se de uma política pública brasileira, ainda são escassas as pesquisas que o contemple totalmente, ou seja, que abordem tanto a primeira, quanto a segunda e a terceira etapa. Além disso, observa-se que nas pesquisas brasileiras encontradas, ainda utiliza-se os termos "Método Canguru", "posição canguru" e "cuidado mãe-canguru" erroneamente como sinônimos, uma vez que cada um destes possui seu significado e peculiaridades.

$\mathrm{O}$ estudo traz como fatores limitadores a escassez de pesquisas realizadas abordando claramente todas as etapas do MC. A implantação das etapas dentro das instituições públicas ainda ocorre de maneira não homogenia, e poucas pos- 
suem a Unidade de Cuidados Intermediários Neonatal Canguru e o acompanhamento ambulatorial na terceira etapa. Observa-se grande quantidade de estudos, principalmente internacionais, acerca da posição canguru. Esta nomenclatura similar favorece a confusão entre os termos, já que a posição canguru é apenas um pilar dentro da proposta do MC.

Espera-se que esta revisão da literatura sirva como incentivo para a realização de novos estu- dos que abordem todas as etapas do MC acerca da temática proposta e promova a reflexão de profissionais da saúde e gestores no sentido de fomentar e ampliar essa prática para maior número de hospitais e maternidades brasileiras. Além disso, foram apontados aspectos facilitadores e dificultadores acerca da amamentação no contexto do MC com objetivo de aprimorar e contribuir para a formulação de políticas públicas voltadas para o cuidado do RNPT.

\section{Colaboradores}

FN Alves, VMGO Azevedo e PCB Wolkers delinearam a metodologia do estudo, além da definição dos termos de busca utilizados. FN Alves realizou a busca na literatura juntamente com a análise das pesquisas encontradas e escrita do artigo. FN Alves, VMGO Azevedo, MRS Moura, DMLM Ferreira, CGA Araújo, C Mendes-Rodrigues e PCB Wollkers realizaram a revisão crítica do estudo, aprovando sua versão final. 


\section{Referências}

1. Vitolo MR. Nutrição: da gestação ao envelhecimento. $2^{\text {a }}$ ed. Rio de Janeiro: Rubio; 2015.

2. Schanler RJ. Outcomes of human milk-fed premature infants. Semin Perinatol 2011; 35(1):29-33.

3. Kliegman RM, Walker WA, Yolken RH. Necrotizing enterocolitis: research agenda for a disease of unknown etiology and pathogenesis. Pediatr Res 1993; 34(6):701-708

4. Holman RC, Stoll BJ, Clarke MJ, Glass RI. The epidemiology of necrotizing enterocolitis infant mortality in the United States. Am J Public Health 1997; 87(12):2026-2031.

5. Schanler RJ, Lau C, Hurst NM, Smith EO. Randomized trial of donor human milk versus preterm formula as substitutes for mothers' own milk in the feeding of extremely premature infants. Pediatrics 2005; 116(2):400-406.

6. Levy I, Comarsca J, Davidovits M, Klinger G, Sirota L, Linder N. Urinary tract infection in preterm infants: the protective role of breastfeeding. Pediatr Nephrol 2009; 24(3):527-531.

7. Vohr BR, Poindexter BB, Dusick AM, McKinley LT, Higgins RD, Langer JC, Poole WK, National Institute of Child Health and Human Development National Research Network. Persistent beneficial effects of breast milk ingested in the neonatal intensive care unit on outcomes of extremely low birth weight infants at 30 months of age. Pediatrics 2007; 120(4):e953-e959.

8. Furman L, Minich N, Hack M. Correlates of lactation in mothers of very low birth weight infants. Pediatrics 2002; 109(4):e57.

9. Rios IJA, Oliveira MBP, Farias PT, Barcellos SF, Tini V. Amamentando o prematuro. In: Hitos SF, Periotto MC. Amamentação: atuação fonoaudiológica. Uma abordagem prática e atual. Rio de Janeiro: Revinter; 2009.

10. Thomas ACP, Lima MRT, Tavares CHF, Oliveira CG Relações afetivas entre mães e recém-nascidos a termo e pré-termo: Variáveis sociais e perinatais. Estud Psicol 2005; 10(1):139-146.

11. Salustiano LPQ, Diniz ALD, Abdallah VOS, Pinto RMC. Factors associated with duration of breastfeeding in children under six months. Rev Bras Ginecol Obstet 2012; 34(1):28-33.

12. Charpak N, Calume ZF, Hamel A. O método mãe canguru pais e familiares de bebês prematuros podem substituir as incubadoras. Chile: McGraw Hill; 1999.

13. Whitelaw A, Stleath K. Myths of the marsupial mother: home care for very low birth infants in Bogota Colombia. Lancet 1985; 1(8439):1206-1208.

14. Brasil. Ministério da Saúde (MS). Secretaria de Atenção à Saúde. Departamento de Ações Programáticas Estratégicas. Atenção humanizada ao recém-nascido de baixo peso: Método Canguru: Manual Técnico. 2a ed. Brasília: MS; 2013.

15. Venancio SI, Almeida H. Método Mãe Canguru: aplicação no Brasil, evidências científicas e impacto sobre o aleitamento materno. J Pediatr 2004; 80(Supl. 5):S173-S180.
16. Nunesa CRN, Campos LG, Lucena AM, Pereira JM, Costa PR, Lima FAF, Azevedo VMGO. Relação da duração da posição canguru e interação mãe filho pré termo na alta hospitalar. Rev Paul Pediatr 2017; 35(2):136-143.

17. Farias SR, Dias FSB, Silva JB, Cellere ALLR, Beraldo L, Carmona EV. Posição canguru em recém-nascidos pré-termo de muito baixo peso: estudo descritivo. Rev Eletr Enf 2017; 19:a15.

18. Menezes MA, Garcia DC, de Melo EV, Cipolotti R. Preterm newborns at Kangaroo Mother Care: a cohort follow-up from birth to six months. Rev Paul Pediatr 2014; 32(2):171-176.

19. Spehar MC, Seidl EMF. Percepções maternas no Método Canguru: contato pele a pele, amamentação e autoeficácia. Psicol Estud 2013; 18(4):647-656.

20. Maia C, Brandao R, Roncalli A, Maranhao H. Length of stay in a neonatal intensive care unit and its association with low rates of exclusive breastfeeding in very low birth weight infants. J Matern Fetal Neonatal Med 2011; 24(6):774-777.

21. Almeida H, Venâncio SI, Sanches MT, Onuki D. The impact of kangaroo care on exclusive breastfeeding in low birth weight newborns. J Pediatr 2010; 86(3):250253.

22. Silva SMS, Segre CAM. Fatores que influenciam o desmame no recém-nascido prematuro. Rev Bras Cresc Desenvolv Hum 2010; 20(2):103-113.

23. Araújo CL, Rios CTF, Santos MH, Gonçalves APF. Método Mãe Canguru: uma investigação da prática domiciliar. Cien Saúde Colet 2010; 15(1):301-307.

24. Lamy Filho F, Silva AA, Lamy ZC, Gomes MA, Moreira ME, Grupo de Avaliação do Método Canguru, Rede Brasileira de Pesquisas Neonatais. Evaluation of the neonatal outcomes of the kangaroo mother method in Brazil. J Pediatr 2008; 84(5):428-435.

25. Freitas JO, Camargo CL. Método Mãe-Canguru: evolução ponderal de recém-nascidos. Acta Paul Enferm 2007; 20(1):75-81.

26. Alves AM, Silva E, Oliveira AC. Early weaning in premature babies participants of the Kangaroo Mother Care. Rev Soc Bras Fonoaudiol 2007; 12(1):23-28.

27. Cabral IE, Rodrigues EC. O método mãe-canguru em uma maternidade do Rio de Janeiro 2000-2002: necessidades da criança e demanda de educação em saúde para os pais. Texto Contexto Enferm 2006; 15(4):629-636.

28. Penalva O, Schwartzman JS. Descriptive study of the clinical and nutritional profile and follow-up of premature babies in a Kangaroo Mother Care Program. J Pediatr 2006; 82:33-39.

29. Neves PN, Ravelli APX, Lemos JRD. Atenção humanizada ao recém-nascido de baixo-peso (método Mãe Canguru): percepções de puérperas. Rev Gaúcha Enferm 2010; 31(1):48-54.

30. Borck M, Santos EKA. Terceira etapa método Canguru: convergência de práticas investigativas e cuidado com famílias em atendimento ambulatorial. Rev Gaúcha Enferm 2010; 31(4):761-768. 
31. Groleau D, Cabral IE. Reconfiguring insufficient breast milk as a sociosomatic problem: mothers of premature babies using the kangaroo method in Brazil. Matern Child Nutr 2009; 5(1):10-24.

32. Cabral IE, Groleau D. Breastfeeding practices after Kangaroo Mother Method in Rio de Janeiro: the necessity for health education and nursing intervention at home. Esc Anna Nery Rev Enferm 2009; 13(4):763771.

33. Braga DF, Machado MM, Bosi ML. Achieving exclusive breastfeeding of premature babies: the perceptions and experience of women from public health services. Rev Nutr 2008; 21(3):293-302.

34. Toma TS, Venâncio SI, Andretto DA. Percepção das mães sobre o cuidado do bebê de baixo peso antes e após implantação do método mãe-canguru em hospital público da cidade de São Paulo, Brasil. Rev Bras Saude Mater Infant 2007; 7(3):297-307.

35. Guimaraes GP, Moticelli M. A formação do apego pais/recém-nascido pré-termo e/ou de baixo peso no método mãe-canguru: uma contribuição da enfermagem. Texto Contexto Enferm 2007; 16(4):626-635.

36. Javorski M, Caetano LC, Vasconcelos MGL, Leite AM, Scochi CGS. As representações sociais do aleitamento materno para mães de prematuros em unidade de cuidado canguru. Rev Latino-Am Enferm 2004; 12(6):890-898.

37. Charpak N, Ruiz-Peláez JG, Fiqueroa Z, Charpak Y. Kangaroo mother versus traditional care for newborn infants $\leq 2000$ grams: a randomized, controlled trial. Pediatrics 1997; 100(4):682-688.

38. Ludington-Hoe SM, Morgan K, Abouelfettoh A. A Clinical guideline for implementation of kangaroo care with premature infants of 30 or more weeks' postmenstrual age. Adv Neonatal Care 2008; 8(3):S3S23.

39. Gathwala G, Singh B, Singh J. Effect of Kangaroo Mother Care on physical growth, breastfeeding and its acceptability. Trop Doct 2010; 40(4):199-202.

40. Thukral A, Sankar MJ, Agarwal R, Gupta N, Deorari AK, Paul VK. Early skin-to-skin contact and breastfeeding behavior in term neonates: a randomized controlled trial. Neonatology 2012; 102(2):114-119.

41. Heidarzadeh $M$, Hosseini MB, Ershadmanesh $M$, Gholamitabar Tabari M, Khazaee S. The effect of kangaroo mother care (KMC) on breast feeding at the time of NICU discharge. Iran Red Crescent Med J 2013; 15(4):302-306.

42. Tully KP, Holditch-Davis D, White-Traut RC, David R, O'Shea TM, Geraldo V. A test of kangaroo care on preterm infant breastfeeding. J Obstet Gynecol Neonatal Nurs 2016; 45(1):45-61.

43. Alfaya C, Schermann L. Depressão materna em mães de bebês recém-nascidos com tratamento intensivo neonatal. Psico 2001; 32(1):115-129.

44. Tabassum ZI, Fortner RT, Pekow P, Dole N, Markenson, Chasan-Taber L. Prenatal Stress, Anxiety, and Depressive Symptoms as Predictors of Intention to Breastfeed Among Hispanic Women. J Womens Health 2011; 20(8):1183-1192.
45. La Marca-Ghaemmaghami P, Ehlert U. Stress during pregnancy: Experienced stress, stress hormones, and protective factors. Euro Psychol 2015; 20(2):102-119.

46. Cruvinel FG, Macedo EC. Interação mãe-bebê pré-termo e mudança no estado de humor: comparação do Método Mãe-Canguru com visita na Unidade de Terapia Intensiva Neonatal. Rev Bras Saude Mater Infant 2007; 7(4):449-455.

47. Bigelow A, Power M, MacLellan-Peters J, Alex M, McDonald C. Effect of mother/infant skin-to-skin contact on postpartum depressive symptoms and maternal physiological stress. J Obstet Gynecol Neonatal Nurs 2012; 41(3):369-382.

48. Alencar AE, Arraes LC, Albuquerque EC, Alves JG. Effect of kangaroo mother care on postpartum depression. J Trop Pediatr 2009; 55(1):36-38.

49. Jayaraman D, Mukhopadhyay K, Bhalla AK, Dhaliwal LK. Randomized controlled trial on effect of intermittent early versus late kangaroo mother care on human milk feeding in low-birth-weight neonates. J Hum Lact 2017; 33(3):533-539.

50. Walty CMRF, Duarte ED. O aleitamento materno de recém-nascidos prematuros após a alta hospitalar. Rev Enferm Cent-t Min 2017; 7:e1689.

51. Gontijo TL, Meireles AL, Malta DC, Proietti FA, Xavier CC. Evaluation of implementation of humanized care to low weight newborns - the Kangaroo Method. J Pediatr 2010; 86(1):33-39.

52. Aires LCP, Santos EKA, Costa R, Borck M, Custódio ZAO. Seguimento do bebê na atenção básica: interface com a terceira etapa do método canguru. Rev Gaúcha Enferm 2015; 36(n. esp.):224-232.
Artigo apresentado em 02/03/2018

Aprovado em 27/12/2018

Versão final apresentada em 29/12/2018 